\title{
Single-session Endodontic Treatment is a Reality in Low-income Areas in Brazil?
}

\author{
Juliana Y Nagata ${ }^{1}$, Fernanda B Fagundes ${ }^{2}$, Eliseu A Münchow ${ }^{3}$, Maria TP Albuquerque ${ }^{4}$
}

\begin{abstract}
Aim: The present study aimed to investigate the total number of visits required to conclude root canal treatments (RCTs) as well as the motivations associated to the choice of dentists practicing in low-income areas of Brazil.

Materials and methods: A total of 3,103 questionnaires were electronically and individually delivered to professionals of Salvador, Sergipe, and Alagoas (Brazil). The questionnaire encompassed sociodemographic data and questions regarding the number of sessions required to conclude RCT. Also, postoperative pain, professional qualification, the use of technological resources, and time for one-visit treatment were evaluated. Data were analyzed using Chi-square and Poisson regression analyses $(p<0.05)$.

Results: A total of 326 responses were obtained with higher prevalence of specialists in the field of endodontics (36.8\%). Dentists reported greater preference for rotary instrumentation (Alagoas 54.6\%, Aracaju 62.1\%, and Salvador 83.5\%), and most of the participants reported multiple visits to treat root canals with the necrotic pulp tissue associated or not to periapical radiolucency, excluding Salvador (53.8\%). Dentists who graduated in public dental schools were less likely to perform RCT of necrotic teeth with periapical lesion in one clinical appointment $(p=0.034)$. The single-session therapy was positively associated to continuing education attendance $(p=0.004)$ and to the occurrence of clinical complications $(p<0.001)$. Dentists who graduated in lato sensu programs were more likely to conclude RCT in less than 60 minutes $(p<0.001)$, although the occurrence of postoperative pain was more likely observed upon this scenario $(p<0.001)$.

Conclusion: Despite the social inequalities in the analyzed area, professionals have been seeking for knowledge by means of continuing education programs and the implementation of technological resources in their clinical routine, although this fact has poorly influenced the acceleration of RCT.

Clinical significances: The total number of visits to conclude endodontic treatment may be influenced by both professional and biological parameters such as the attendance to postgraduation programs and the use of technology as well as to the biological condition of the pulp and the occurrence of postoperative complications.
\end{abstract}

Keywords: Continuing education, Endodontics, Questionnaire, Single visit.

The Journal of Contemporary Dental Practice (2020): 10.5005/jp-journals-10024-2861

\section{INTRODUCTION}

The main goal of endodontic treatments is undoubtedly the complete eradication of root canal infection or a significant decrease in the microbiota population to levels of compatibility with periapical tissues. ${ }^{1,2}$ It is well established that the presence of a microbial colonization into the root canal system (RCS) might impact in the predictability of the endodontic treatment success, so that several irrigation devices (e.g., PIPS, PUI, Easy clean, Xp finisher), instrumentation techniques, endodontic file systems, as well as the use of clinical microscopy with effective irrigant disinfectants have all emerged to improve root canal disinfection. Worth mentioning, the introduction of foregoing approaches/technologies allowed the professionals to perform endodontic treatments following a singlevisit modality, ${ }^{3-5}$ in which all the treatment (i.e., pulp chamber access, root canal(s) instrumentation, disinfection of the intracanal system, filling and sealing of the tooth) is completed in one clinical appointment. However, the long-term endodontic treatment success comparing single and multiple sessions is still provoking a wide discussion in the field, especially under the circumstances of a necrotic pulp tissue. ${ }^{6-8}$

Clinical studies have demonstrated the absence of significant differences regarding postoperative pain and success rate (88-96\%) for cases with the necrotic pulp tissue submitted to root canal treatment (RCT) both in single- or multiple-visit appointments. ${ }^{4,7,9}$ However, some investigations have demonstrated the professionals'
'Dentistry Department, Endodontics, Federal University of Sergipe, Lagarto, Sergipe, Brazil

${ }^{2}$ Department of Clinical Dentistry, Endodontics, Federal University of Bahia, Salvador, Bahia, Brazil

${ }^{3}$ Department of Conservative Dentistry, Federal University of Rio Grande do Sul, Porto Alegre, Rio Grande do Sul, Brazil

${ }^{4}$ Department of Clinical Dentistry, Endodontics, Federal University of Bahia, Salvador, Bahia, Brazil

Corresponding Author: Juliana Y Nagata, Dentistry Department, Endodontics, Federal University of Sergipe, Lagarto, Sergipe, Brazil, e-mail: ju_nagat@hotmail.com

How to cite this article: Nagata JY, Fagundes FB, Münchow EA, et al. Single-session Endodontic Treatment is a Reality in Low-income Areas in Brazil? J Contemp Dent Pract 2020;21(6):657-665.

Source of support: Nil

Conflict of interest: None

preferences concerning single or multiple visit during their daily routine, ${ }^{10-12}$ finding a very strong influence of the professional clinical expertise and also to the dynamic appointments scheduling adopted by the clinics. ${ }^{12}$ In Brazil, most of the population (70\%) depends exclusively on the public health care. ${ }^{13}$ Particularly concerning endodontic treatment performed in public services, almost all of them have been concluded in three clinical 
appointments requiring 71 days to complete the treatment, regardless of the pathological condition of the pulp tissue. ${ }^{13}$ This might be partially explained by the precarious materials used, the great amount of patients demanding endodontic treatment, the short time available for each RCT appointment, and to the lack of technological resources to perform the endodontic treatment, which may cloak the real number of visits required for each case.

Remarkably, recent technological progress in endodontics has demonstrated advantages of the single-visit modality, shortening the time required to conclude an endodontic treatment and avoiding the unlikely contamination between sessions, usually associated to multisession appointments. ${ }^{14-17}$ Noteworthy, the single-visit endodontic treatment has become a new trend among endodontists, since a large number of professionals have been applying rotary/reciprocating instruments on their clinical practice routines, speeding up the root canal preparation and leading the professionals to increase the efficiency of the treatment. ${ }^{15,16}$ Meanwhile, few studies have investigated how much time has been required to conclude an endodontic therapy in the single-visit appointment modality and whether this shortened time influences on the long-term success concerning infection eradication. ${ }^{14,16}$ Moreover, it would be of interest investigating whether technology and professional qualification have an influence on the choices for performing single-visit RCT.

Considering both the reality of each clinical environment and the ideal treatment for each pathological condition, it is important to understand the factors that have been pondered by the professionals in the decision regarding the number of visits and which postoperative complications have been observed in endodontic treatment performed in low-income regions of Brazil. This study aimed to investigate the preferences of dentists concerning number of visits to conclude endodontic treatment as well as the presence of postoperative pain, reasons for each choice, use of technological resources, and time for one-visit treatment in low-income regions of northeastern Brazil.

\section{Materials and Methods}

The Research Ethics Committee of both Federal University of Sergipe (Acceptance number: 51153615.9.000.5546) and Federal University of Bahia (Acceptance number: 51153615.9.000.5546) approved this cross-sectional study. The present inquiry was implemented through a double-part questionnaire: first, it consisted of demographic data of each participant (e.g., age, gender, working city, graduation institution, years of dental practice, continuous education, and qualification in endodontics); and second, it was composed of questions about the use of endodontic technology (e.g., use of rotary systems), occurrence of clinical complications, number of visits to perform RCT, time to conclude the treatment per tooth type, and existence of postoperative pain in cases of single- and multiple-visit treatment.

Part of the questionnaires was distributed individually to dentists who perform endodontic treatment in the city of Salvador (Bahia state) and in the main cities of Sergipe state. All the participants received a brief explanation on the objectives of the survey and its confidentiality (no identification) and request for participation. Professionals were given the option to opt out of answering the questionnaire. The questionnaires were collected on the next day, immediately separated from the consent form, and put in an envelope to keep the identity of the participants anonymous. The other part of the questionnaires was sent electronically to the professionals registered in the Regional Council of Alagoas State. The collected data were presented through descriptive statistics and analyzed with the statistical software IBM SPSS Statistics (version 22; IBM) using chi-square and Poisson regression analyzes, considering the significance level of $p<0.05$.

\section{Results}

A total of 3,103 questionnaires were distributed to dentists of three northeastern states in Brazil. Overall, 326 professionals accepted to participate in this research, including 118 dentists of Alagoas state, 116 from Sergipe state, and 92 from the city of Salvador (Bahia state). From the 326 dentists who answered the questionnaire, 307 fully completed the questionnaire, representing a $94 \%$ full-response rate.

A greater number of dentists attended public dental school during graduation (59.6\%) (Table 1). Most of the respondents have concluded their graduation in dentistry in less than 10 years ( $60 \%)$, with nearly $17 \%$ of the sample having more than 20 years of experience in the field. Concerning continuous education in Endodontics, most of the interviewed sample ( 74\%) attended a postgraduation program, which was distributed as follows: (1) only a shorter program with duration lower than 1 year (26.7\%); (2) only a longer program (Lato sensu) with duration of up to 2 years (29.3\%); (3) only Stricto sensu program(s) (4.2\%); and (4) shorter and longer programs (13.7\%). From the total sample, approximately $39 \%$ perform RCT using the rotary system. The greater majority of dentists (83.4\%) answered that they do not perform RCT of necrotic teeth with periapical lesion in one clinical appointment. However, in the case of necrotic teeth without periapical lesion, the frequency of dentists unfavorable to that procedure was lower ( 61\%). The frequency of dentists who perform RCT of necrotic teeth with or without periapical lesion in one clinical appointment is greater for incisors (82.1\%) as compared to premolar (77.9\%) and molar (70.4\%) teeth (Table 2). Last, from those who perform RCT in one appointment, only $12.4 \%$ of the sample has never faced any clinical complication, opposed by nearly $66 \%$ and $21.5 \%$ of dentists who experienced up to two or more than two clinical complications, respectively (Table 1). The most common complications answered by the respondents are presented in Figure 1, which were triggered by the failure in the disinfection due to the lack of using intracanal medication (33.4\%), flare-up (25\%), the incomplete repair of periapical tissues (21.2\%), and tooth pain (16.3\%).

Two regression analyzes were performed in the present study, taking into consideration as the fixed variable the dentists who perform RCT of necrotic teeth in one clinical appointment (Table 1). While the first regression considered only teeth with periapical lesion, the second considered teeth without any periapical lesion. Considering the first fixed variable (i.e., teeth with periapical lesion), the time since graduation and the use of rotary system were not significantly associated to the variable ( $p \geq 0.070)$, whereas the school of graduation (i.e., public or private), the attendance of continuing education in endodontics, and the number of clinical complications were all significantly associated to that variable $(p \leq 0.034)$. Dentists who graduated in a public school were less likely to perform RCT of necrotic teeth with periapical lesion in one appointment $(p=0.034)$. On the other hand, attending a continuing education in endodontics made the dentists more likely to perform RCT under that condition ( $p=0.004)$. The only exceptions were related to dentists who attended only Stricto sensu programs, in which none of them seemed favorable to the procedure, and the professionals who attended only shorter programs. Interestingly, 
Table 1: Crude prevalence ratios (PR) for factors associated with dentists performing RCT of necrotic teeth with or without periapical lesion in one appointment, from three northeastern cities in Brazil: Salvador-BA, Aracaju-SE, and Maceió-AL $(N=307)$. Poisson regression analysis

\begin{tabular}{|c|c|c|c|c|c|c|c|c|}
\hline \multirow[b]{2}{*}{ Independent variable } & \multicolumn{2}{|c|}{$n(\%)$} & \multirow[b]{2}{*}{$P R$ (IC 95\%) } & \multirow[b]{2}{*}{$p$ value } & \multicolumn{2}{|c|}{$n(\%)$} & \multirow[b]{2}{*}{ PR (IC 95\%) } & \multirow[b]{2}{*}{$p$ value } \\
\hline & No & Yes & & & No & Yes & & \\
\hline \multicolumn{9}{|l|}{ Years since graduation } \\
\hline$>20$ & $44(14.3)$ & $8(2.6)$ & 1 & 0.401 & $35(11.4)$ & $17(5.5)$ & 1 & 0.726 \\
\hline $16-20$ & $23(7.5)$ & $4(1.3)$ & $1.01(0.83-1.22)$ & & $17(5.5)$ & $10(3.3)$ & $0.94(0.66-1.32)$ & \\
\hline $11-15$ & $40(13.0)$ & $4(1.3)$ & $1.07(0.93-1.25)$ & & $28(9.1)$ & $16(5.2)$ & $0.95(0.71-1.27)$ & \\
\hline $6-10$ & $72(23.5)$ & $19(6.2)$ & $0.94(0.80-1.09)$ & & $51(16.6)$ & $40(13.0)$ & $0.83(0.64-1.08)$ & \\
\hline $1-5$ & $77(25.1)$ & $16(5.2)$ & $0.98(0.84-1.14)$ & & $56(18.2)$ & $37(12.1)$ & $0.90(0.70-1.15)$ & \\
\hline \multicolumn{9}{|l|}{ Graduation school } \\
\hline Private & 95 (30.9) & $29(9.4)$ & 1 & 0.015 & $76(24.8)$ & $48(15.6)$ & 1 & 0.911 \\
\hline Public & $161(52.4)$ & $22(7.2)$ & $1.15(1.03-1.28)$ & & $111(36.2)$ & $72(23.5)$ & $0.99(0.83-1.19)$ & \\
\hline \multicolumn{9}{|l|}{ Continuing education in endodontics } \\
\hline None & $77(25.1)$ & $3(1.0)$ & 1 & $<0.001$ & $69(22.5)$ & $11(3.6)$ & 1 & $<0.001$ \\
\hline Lato and Stricto sensu programs & $6(2.0)$ & $3(1.0)$ & $0.69(0.44-1.10)$ & & $5(1.6)$ & $4(1.3)$ & $0.64(0.36-1.16)$ & \\
\hline Master of science/shorter program & $20(6.5)$ & $13(4.2)$ & $0.63(0.48-0.83)$ & & $15(4.9)$ & $18(5.9)$ & $0.53(0.36-0.77)$ & \\
\hline Master of science/PhD programs & $5(1.6)$ & $0(0)$ & $1.04(1.00-1.09)$ & & $3(1.0)$ & $2(0.7)$ & $0.70(0.34-1.43)$ & \\
\hline Master of science only & $8(2.6)$ & $0(0)$ & $1.04(1.00-1.09)$ & & $4(1.3)$ & $4(1.3)$ & $0.58(0.29-1.17)$ & \\
\hline Lato sensu only & $69(22.5)$ & $21(6.8)$ & $0.80(0.71-0.90)$ & & $42(13.7)$ & $48(15.6)$ & $0.54(0.43-0.69)$ & \\
\hline Shorter program only & $71(23.1)$ & $11(3.6)$ & $0.90(0.82-0.99)$ & & $49(16.0)$ & $33(10.7)$ & $0.69(0.57-0.85)$ & \\
\hline \multicolumn{9}{|l|}{ Rotatory system use } \\
\hline No & $148(48.2)$ & 39 (12.7) & 1 & 0.008 & $114(37.1)$ & $73(23.8)$ & 1 & 0.982 \\
\hline Yes & $108(35.2)$ & $12(3.9)$ & $1.14(1.03-1.25)$ & & $73(23.8)$ & $47(15.3)$ & $1.00(0.83-1.20)$ & \\
\hline \multicolumn{9}{|l|}{ Number of clinical complications } \\
\hline More than two & $62(20.4)$ & $3(1.0)$ & 1 & $<0.001$ & $48(15.8)$ & $17(5.6)$ & 1 & $<0.001$ \\
\hline Up to two & $180(59.2)$ & $22(7.2)$ & $0.93(0.87-1.00)$ & & $135(44.4)$ & $67(22.0)$ & $0.92(0.77-1.10)$ & \\
\hline None & $12(3.9)$ & $25(8.2)$ & $0.33(0.21-0.53)$ & & $3(1.0)$ & $34(11.2)$ & $0.11(0.04-0.33)$ & \\
\hline
\end{tabular}

dentists who perform RCT of necrotic teeth with periapical lesion in one appointment demonstrated a significantly lower prevalence ratio of facing clinical complications during the treatment $(p<$ 0.001 ), as compared with dentists who do not perform that clinical procedure.

Regarding dentists who perform RCT of necrotic teeth without periapical lesion in one appointment, only two factors were significantly associated to this fixed variable: attending a continuous education in endodontics ( $p=0.001)$ and the number of clinical complications faced by the dentist $(p<0.001)$. The other factors were not associated to the variable ( $p \geq 0.116$ ). According to the regression analyzes, attending any type of continuing education in endodontics seems to positively stimulate the professional to perform the RCT of the teeth in one appointment $(p=0.001)$, with the longer and more specialized the program, the greater the prevalence ratio observed. Last, performing the RCT in one appointment seems to contribute for less occurrence of clinical complications $(p<0.001)$, especially more than two complications, as compared with dentists who do not follow this endodontic treatment protocol.

Table 2 shows the association between the total time spent by dentists to perform the RCT of necrotic teeth with or without periapical lesion in one appointment and some independent variables (i.e., rotary system use, continued education in endodontics, pain in cases of necrotic teeth with or without periapical lesion). In the case of incisors, there was not any significant association between the independent variables and the total time spent in performing the RCT ( $p \geq 0.118)$. For premolar and molar teeth, the use of the rotary system and the occurrence of pain after RCT of necrotic teeth with periapical lesion were both significantly associated to the duration time of the RCT ( $p \leq 0.045)$. From professionals who perform the RCT of premolar and molar teeth faster than 60 minutes, most of them do not use the rotary system ( $p \leq 0.045$ ); conversely, from the professionals who take longer time to finish the endodontic treatment, the use or not of a rotary system does not seem to influence the total time spent by the dentist. Concerning the occurrence of pain after the RCT of premolar and molar teeth with necrosis and periapical lesion in one appointment, dentists who take longer than 60 minutes in finishing the endodontic treatment tend to obtain more asymptomatic outcomes than the professionals who perform the RCT in shorter periods of time $(p \leq 0.048)$.

\section{Discussion}

Biological, clinical, and technical aspects may influence the professionals' decision on the number of sessions/clinical appointments to conclude endodontic treatment over the past several years. ${ }^{6,17,18}$ Aspects regarding the occurrence of postoperative complications, periapical healing, and long-term success have shown no difference unlikely the treatment regimen (single-visit or multiple-visit treatment), both for vital and nonvital teeth. ${ }^{6,19,20}$ Many of these studies have been carried out using animal models, randomized clinical trials, and systematic reviews; however, few studies have compared new tendencies of RCT in 


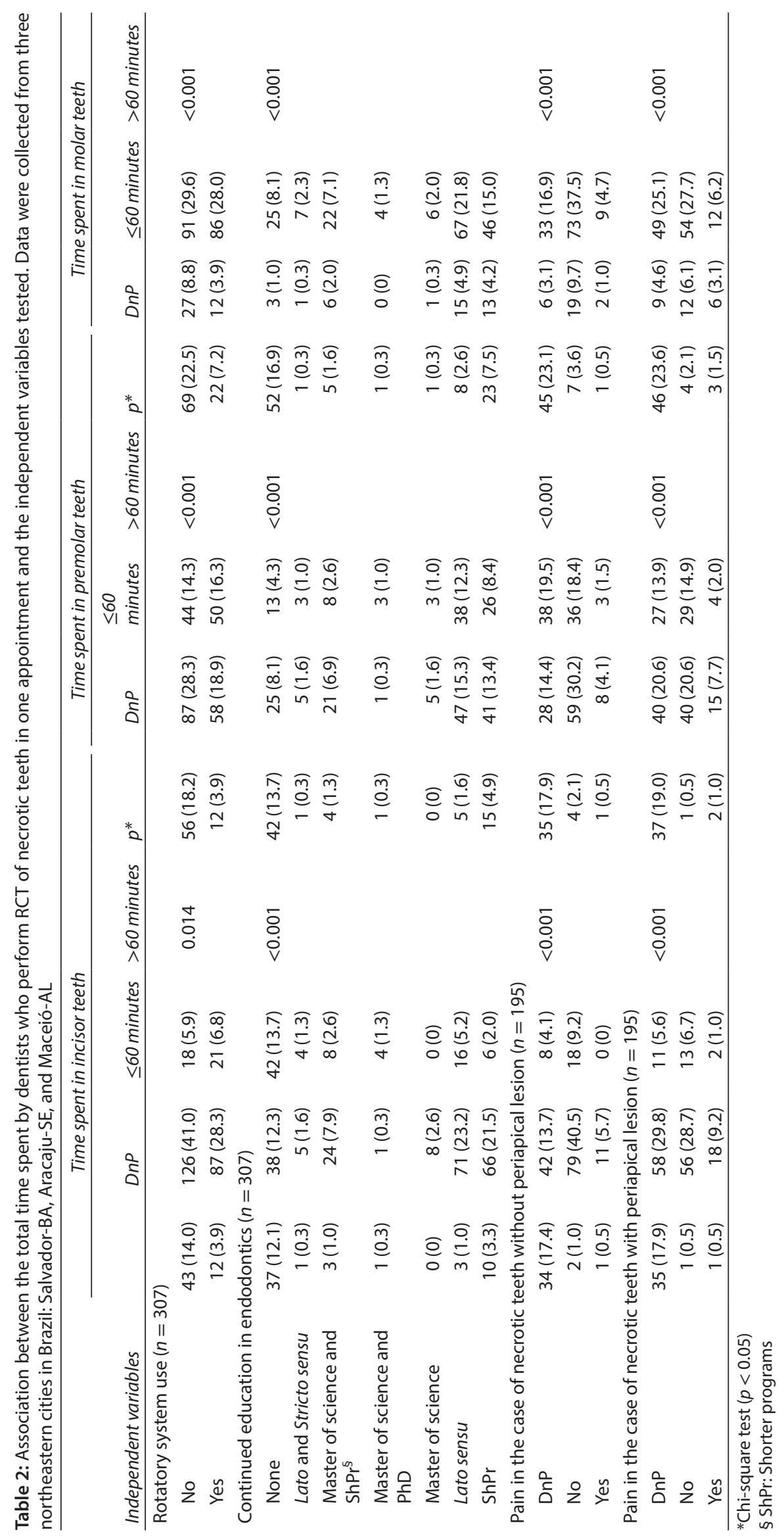




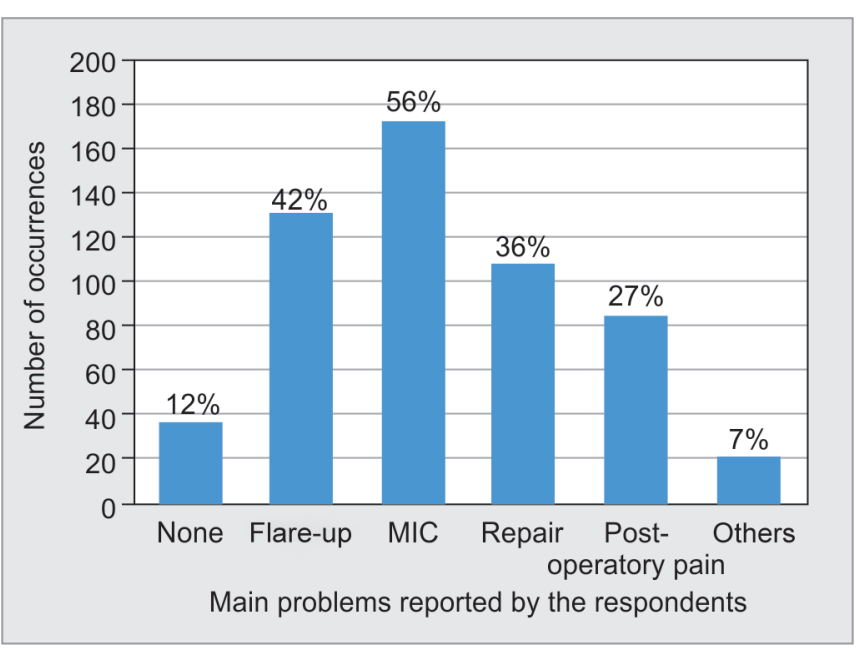

Fig. 1: Frequency and distribution of the main problems reported by the respondents concerning the performance of RCT of necrotic teeth in one clinical appointment

association with the social conditions of the population, ${ }^{21}$ which may affect the RCT protocol and perhaps the choice of endodontic instruments (i.e., rotary/reciprocating files) by the professional. Taking this into consideration, the present assessment contributed to demonstrate an overview of current endodontic treatments in association to the factors that may influence on those decisions, but in a well-known area possessing high social inequalities with most of the population, which live under low-income conditions in Brazil.

With regard to the pathological condition, the necrotic pulp tissue with or without periapical radiolucency has played important discussions in the number of sessions for the RCT completion scenario. ${ }^{4,6,7}$ The major drawback concerning the treatment of necrotic teeth relies on the fact that root canal infection is more difficult to eradicate, representing a challenge to the professional, especially following the single-visit treatment modality. ${ }^{18-20}$ In the present study, the number of clinical appointments required to complete the RCT was evaluated considering three possible scenarios: teeth with vital pulp tissue, teeth with necrotic pulp tissue associated to periapical radiolucency and necrotic teeth with no periapical radiolucency. Overall, the single-visit endodontic treatment for vital pulp cases, was the preferred option among the participants. Conversely, regarding RCT of necrotic teeth with or without periapical lesion, in the city of Salvador (Bahia state) the respondents were divided between single-visit and multiplevisit choices, demonstrating a slightly higher preference for the multiple-visit in cases associated to periapical lesions (59.3\%); while in the other states (Alagoas and Sergipe), it was observed a greater tendency for multiple-visit RCT in cases of necrotic pulps with the periapical lesion (93.9\% in Sergipe state vs $90.4 \%$ in Alagoas).

The discrepancy among the states might be related to the level of the instructions by the respondents (i.e., postgraduation courses) involved in this research as well as to the distinctive endodontic treatment philosophy adopted by different dental schools that may influence on the choice for each clinical condition. Moreover, social circumstances of the population at professional's work environment, may conduct to multiple-visit endodontic treatments choice due to the lack of time and also technological resources (e.g., rotary and/or reciprocating systems), essential devices to optimize and enable single-visit treatments, since there is a huge demand for dentistry care in the public health.

Overall, several new endodontic technologies have been implanted in endodontics throughout the last decades (e.g., rotary and reciprocating systems, operatory microscopy, ultrasound devices), encouraging professionals to perform singlevisit treatment including the cases associated to the periapical lesion. ${ }^{719}$ In this context, the current study assessed the use of rotary/reciprocating instruments by professionals performing single-visit endodontic treatment, and it was found that most of the professionals apply the aforementioned instruments during RCT (54.6-83.5\%). The mentioned data resemble previous studies performed in developed countries such as the United States, England, and Wales, in which general dentists also described the use of nickel-titanium rotary instruments in the following rates: 60 , 90 , and $54.1 \%$, respectively, during RCT. ${ }^{22-24}$ In the United States, the dentists with less than 2 years of practice were more likely to use mechanization; while in Wales, the professionals decided not to adopt rotary instrumentation due to its costs, and in England, the use of hand files have been associated to rotary ones. ${ }^{22-24}$ Remarkably, in the present investigation, it was not observed a significant correlation between the use of rotary instrumentation and the predilection for single-visit treatment in cases of necrotic pulp with or without periapical lesion, showing weak influence of mechanization in decreasing time of RCT. In the meantime, significant association was observed between the professionals who use technology in one appointment and the socioeconomic developing index of the evaluated state. Briefly, Alagoas state presented the lowest percentage $(54.6 \%)$ of rotary instruments use when compared to Sergipe (62.1\%) and Salvador (83.5\%), probably because the latter were demonstrated to possess a greater individual development income, according to the Brazilian National Survey and Geography Institute. ${ }^{25}$

Concerning the occurrence of postoperative pain, it is understood that pain may occur regardless of professionals' preferences for RCT in single- or multiple-visit modalities. One may consider that the presence of pain after RCT may be caused by extrusion of dentin residues and microorganisms through the apical foramen during instrumentation, although the literature has pointed out no differences related to postoperative pain comparing single- and multiple-visit treatment. $8,19,20$ Conversely, the present research found a correlation between single-visit treatment and postoperative pain $(p<0.001)$. In Salvador, most of the dentists reported absence of postoperative pain for all the pathological conditions of the pulp tissue, although the numbers showed progressive decrease as greater the level of infection was observed. Differently, 58.3\% of the participants have not observed pain in vital pulp cases treated in single session in Alagoas, although necrotic root canals with or without a periapical lesion have not been frequently treated in single-visit appointments. It is also worth to mention that having accomplished a continuous education program (mainly Lato sensu programs in endodontics) was strongly related to reduce the time of a RCT. On the other hand, professionals who had attended Stricto sensu programs were shown to be more cautious when performing single-visit treatments, though preferring to use an intracanal medication between sessions to prevent possible clinical complications.

Another investigated factor that may interfere in the clinical decision for single- or multiple-visit appointment refers to the 
time to conclude the treatment in single-visit RCT, which may be influenced by the anatomical conditions of the tooth, number of root canals, and the appropriateness/convenience for both the patient and the professional. Most of the studies have demonstrated that teeth with less anatomical variations are easier to treat so that the time for single-visit RCT is considerably lower. ${ }^{3,16}$ Thus, in the current study, most of the professionals reported the practice of single session in approximately 60 minutes to treat incisors and premolars (49.2 and 39.3\%, respectively)_but more than 60 minutes when dealing with molars. This reduced time to perform RCT was significantly more prevalent among the professionals who attended a continuous education course, since they possibly have been using technological resources complemented by their greater training. Single-visit treatment presents clear benefits related to greater convenience both to the patient and professional in the modern lifestyle of population, including the shorter time needed to conclude the treatment, the lower cost to the dentist and patient itself, and the unlikely possibility of contamination/ microleakage between the clinical appointments. Notwithstanding, proper discussion of the aforementioned factors relies on some dissonances regarding lower volume and time of chemical substance action as well as the necessity of greater professional accuracy and experience, especially under work conditions that lack in technological resources. On the other hand, despite recent studies have pointed to a greater tendency on performing RCT in single-visit appointments, ${ }^{9,12}$ it may not be always performed according to working conditions (public or private service), patient routine and behavior (busy and/or anxious patient, limited mouth opening), anatomical conditions of the tooth, and dentist training. ${ }^{3}$ In this situation where both the patient and the professional may get tired with longer appointments, as well as in the presence of acute root canal inflammation, it has been indicated the use of intracanal medication to complement disinfection and to reduce pain. ${ }^{26,27}$ In addition, studies have demonstrated that RCT performed in shorter time may reflect in operatory errors (e.g., tooth perforation, separation of endodontic files, missing root canals, remaining pulp tissues, and/or microorganisms), thus compromising the long-term success of the treatment.

Brazil possesses low-income areas like the northeastern region, where most of the population depends on public health services with precarious resources, limiting treatment alternatives, and consequently influencing professionals' decisions during RCT. Previous studies performed with north and northeastern population of Brazil demonstrated that variables such as gender (women), education level (less educated population), age (young people), and skin color (black) worsen the difficulties to access oral health services when compared to the population of south and southeastern areas of Brazil. ${ }^{28}$ This deficiency of proper oral health service to all population may frequently lead to tooth loss events, since extraction represents an immediate solution to pain relief with low cost and easier access to patient when compared to RCT. ${ }^{29,30}$ Missing teeth in the oral cavity will consequently cause high impact in patient self-perception of oral health, making the analyzes of the obtained results an important basis for the authorities to implement public polices aiming to improve the quality of the treatment in public services. Hereafter, it is worth to mention that this study should be expanded to other Brazilian states in other to obtain a bigger sample and attain a more reliable data, providing to both dentists and political authorities a prospect about the RCT profile and achieve better treatment for the population.

\section{Conclusion}

Notwithstanding the high social inequalities, it was possible to observe the application of new tendencies in endodontic treatment by the professionals mainly the implementation of single-visit appointment at the daily routine, the attendance to postgraduation courses, and the insertion of rotary/reciprocating instruments in the daily clinical routine.

\section{Future Scope}

The real features responsible for professional's choice between single- or multiple-visit root canal therapy in low-income areas of Brazil were not clear in this study; so, these factors should be further studied and long-termed observed. A forthcoming comparison including the same topic presented in this study should take place in the future to analyze whether the evolution in endodontics technology will reach these low-income areas and the single session will be a reality since it is more cost-effective worthy. Thus, future wider and deeper investigations would contribute to show concrete data to reinforce the necessity of continuous professional training and to government authorities for the importance to provide conditions to make the number of sessions decision a biological choice and not an environmental one in the endodontic treatment.

\section{Clinical Significance}

The number of visits to conclude endodontic treatment may be influenced by the attendance to postgraduation programs, use of technology, biological condition of the pulp, and occurrence of postoperative complications.

\section{References}

1. Siqueira JF, Rôças IN. Clinical implications and microbiology of bacterial persistence after treatment procedures. J Endod 2008;34(11):1291-1301. DOI: 10.1016/j.joen.2008.07.028.

2. Zandi H, Petronijevic N, Mdala I, Kristoffersen AK, Enersen M, Rôças IN et al. Outcome of endodontic retreatment using 2 root canal irrigants and influence of infection on healing as determined by a molecular method: a randomized clinical trial. J Endod 2019;45(9):1089-1098. DOI: 10.1016/j.joen.2019.05.021.

3. Edionwe Jl, Shaba OP, Umesi DC. Single visit root canal treatment: a prospective study. Niger J Clin Pract 2014;17(3):276-281. DOI: 10.4103/1119-3077.130210.

4. Paredes-Vieyra J, Enriquez FJ. Success rate of single- versus two-visit root canal treatment of teeth with apical periodontitis: a randomized controlled trial. J Endod 2012;38(9):1164-1169. DOI: 10.1016/j. joen.2012.05.021.

5. Eyuboglu TF, Olkay K, Ozcan M. A clinical study on single-visit root canal retreatments on consecutive 173 patients: frequency of periapical complications and clinical success rate. Clin Oral Investig 2017;21(5):1761-1768. DOI: 10.1007/s00784-016-1957-2.

6. Schwendicke F, Göstemeyer G. Single-visit or multiple-visit root canal treatment: Systematic review, meta-analysis and trial sequential analysis. BMJ Open 2017;7(2):e013115. DOI: 10.1136/bmjopen-2016013115.

7. Moreira MS, Anuar ASNS, Tedesco TK, et al. Endodontic treatment in single and multiple visits: an overview of systematic reviews. J Endod 2017;43(6):864-870. DOI: 10.1016/j.joen.2017.01.021

8. Riaz A, Maxood A, Abdullah S, et al. Comparison of frequency of postobturation pain of single versus multiple visit root canal treatment of necrotic teeth with infected root canals. A randomized controlled trial. J Pak Med Assoc 2018;68(10):1429-1433. 
9. Manfredi M, Figini L, Gagliani M, et al. Single versus multiple visits for endodontic treatment of permanent teeth. Cochrane Database Syst Rev 2016;12(12):CD005296. DOI: 10.1002/14651858.CD005296. pub3.

10. Wong AWY, Zhang S, Zhang CF, et al. Perceptions of single-visit and multiple-visit endodontic treatment: a survey of endodontic specialists and general dentists in Hong Kong. J Investig Clin Dent 2016;7(3):263-271. DOI: 10.1111/jicd.12154.

11. Sathorn C, Parashos P, Messer H. Australian endodontists' perceptions of single and multiple visit root canal treatment. Int Endod J 2009;42(9):811-818. DOI: 10.1111/j.1365-2591.2009.01587.x.

12. Al-Nahlawi T, Doumani M, Alalo HA, et al. Dentists' knowledge, attitude and practice of root canal treatment procedure: surveybased research. J Contemp Dent Pract 2019;20(3):347-354. DOI: 10.5005/jp-journals-10024-2521.

13. Saliba NA, Nayme JGR, Moimaz SAS, et al. Organization of the demand for a centre of dental specialties. Rev Odontol UNESP 2013;42(5):317323. DOI: 10.1590/S1807-25772013000500001.

14. Rabello DGD, Corazza BJM, Ferreira LL, et al. Does supplemental photodynamic therapy optimize the disinfection of bacteria and endotoxins in one-visit and two-visit root canal therapy? a randomized clinical trial. Photodiagnosis Photodyn Ther 2017;19: 205-211. DOI: 10.1016/j.pdpdt.2017.06.005.

15. Pasqualini D, Corbella S, Alovisi M, Taschieri S, Del Fabbro M, Migliaretti $\mathrm{G}$, et al. Postoperative quality of life following single-visit root canal treatment performed by rotary or reciprocating instrumentation: a randomized clinical trial. Int Endod J 2016;49(11):1030-1039. DOI: 10.1111/iej.12563.

16. Makanjuola JO, Umesi DC, Oderinu OH. Comparison of the incidence of flare-up and time efficiency in single visit root canal treatment employing either rotary or manual step-back canal preparatory technique. Niger Postgrad Med J 2018;25(2):100-104. DOI: 10.4103/ npmj.npmj_8_18.

17. Almeida DO, Chaves SCL, Souza RA, et al. Outcome of single- vs multiple-visit endodontic therapy of nonvital teeth: a metaanalysis. J Contemp Dent Pract 2017;18(4):330-336. DOI: 10.5005/ jp-journals-10024-2041.

18. Alomaym MA, Aldohan MM, Alharbi M, et al. Single versus multiple sitting endodontic treatment: incidence of postoperative pain - a randomized controlled trial. J int Soc prevent Communit Dent 2019;9(2):172-177. DOI: 10.4103/jispcd.JISPCD_327_18.
19. Wong AW, Zhang $\mathrm{C}$, Chu $\mathrm{CH}$. A systematic review of nonsurgical single-visit versus multiple-visit endodontic treatment. Clin Cosmet Investig Dent 2014;6:45-56. DOI: 10.2147/CCIDE.S61487.

20. Patil AA, Joshi SB, Bhagwat SV, et al. Incidence of postoperative pain after single visit and two visit root canal therapy: a randomized controlled trial. J Clin Diagn Res 2016;10(5):ZC09-ZC12. DOI: 10.7860/ JCDR/2016/16465.7724.

21. Albuquerque MTP, Silva JV, Poppe DJO, et al. Endodontic tendencies in a very-low-income population area of northeastern Brazil. Int J Dent 2019. 9543593. DOI: 10.1155/2019/9543593.

22. Palmer NOA, Ahmed M, Grieveson B. An investigation of current endodontic practice and training needs in primary care in the north west of England. Br Dent J 2009;206(22):1-6. DOI: 10.1038/ sj.bdj.2009.473.

23. Bird DC, Chambers D, Peters OA. Usage parameters of nickeltitanium rotary instruments: a survey of endodontists in the United States. J Endod 2009;35(9):1193-1197. DOI: 10.1016/j.joen.2009. 05.027.

24. Locke M, Thomas MB, Dummer PMH. A survey of adoption of endodontic nickel-titanium rotary instrumentation part 1: general dental practitioners in Wales. Br Dent J 2013;214(6):1-10. DOI: 10.1038/ sj.bdj.2013.108.

25. Household income in Brazil at 2018 [Internet]. Brazil: IBGE [cited 2018]. Available from: https://g1.globo.com/economia/noticia/2019/02/27/ renda-domiciliar-per-capita-no-brasil-foi-de-r-1373-em-2018mostra-ibge.ghtml.

26. Kawashima N, Wadachi R, Suda H, et al. Root canal medicaments. Int Dent J 2009;59(1):5-11.

27. Mohammadi Z, Farhad A, Tabrizizadeh M. One-visit versus multiplevisit endodontic therapy-a review. Int Dent J 2006;56(5):289-293. DOI: 10.1111/j.1875-595x.2006.tb00103.x.

28. Vale EB, Mendes ACG, Moreira RS. Self-perceived oral health among adults in northeastern Brazil. Rev Saude Publica 2013;47(suppl 3): 98-108. DOI: 10.1590/s0034-8910.2013047004893.

29. Vargas AMD, Paixão $\mathrm{HH}$. The loss of teeth and its meaning in the quality of life of adults who use the municipal oral health services of the boa Vista health center, in Belo Horizonte. Ciência Saúde Coletiva 2005;10(4):1015-1024. DOI: 10.1590/S1413-81232005000400024.

30. Al-Madi EM, AI Saleh SA, Bukhary SM, et al. Endodontic and restorative treatment patterns of pulpally involved immature permanent posterior teeth. Int J Dent 2018. 2178535. DOI: 10.1155/2018/2178535. 


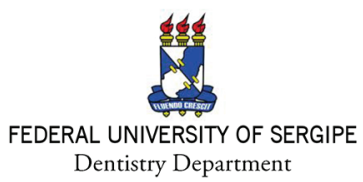

1. Demographic Data

1.1. Age: years

1.2. Gender:

( ) Masculine

( ) Feminine

1.3. City:

1.4. Graduation Institution:

1.5. Year of Graduation:

1.6. Do you have any qualification in Endodontics?

( ) No, but I do root canal treatment.

( ) Yes. What kind of qualification?

( ) Short Program ( ) Lato sensu Program

( ) Master of Science ( ) PhD Program

1.7. Did you attend to any continuing education course in Endodontics in the last two years?

( ) Yes ( ) No

\section{Endodontic Treatment}

2.1. How many sessions do you think are necessary to conclude the treatment of a VITAL PULP TISSUE?
( ) 1 session
( ) 2 sessions
( ) 3 or more sessions

2.2. Would you perform the treatment of NON-VITAL PULP TISSUE WITHOUT PERIAPICAL LESION in one session?

( ) Yes ( ) No

2.3. Would you perform the treatment of NON-VITAL PULP TISSUE WITH PERIAPICAL LESION in one session?

( ) Yes ( ) No

2.4. How many sessions do you think are necessary to conclude the treatment of a NONVITAL PULP TISSUE WITHOUT PERIAPICAL LESION?
( ) 1 session
( ) 2 sessions
( ) 3 or more sessions

Contd... 
Contd...

2.5. How many sessions do you think are necessary to conclude the treatment of a NON-

VITAL PULP TISSUE WITH PERIAPICAL LESION?
( ) 1 session
( ) 2 sessions
( ) 3 or more sessions

2.6. Which complications do you think could occur in the treatment of NON-VITAL PULP in one session?

( ) No problem

( ) Flare-up

( ) The use of intracanal medicament between the sessions is important

( ) Problem in the periapical repair deficiency

( ) Postoperative pain

( ) Others. Which ones?

2.7. Which instruments do you generally use to perform root canal treatment?

( ) Gates-Glidden drills

( ) Rotary files. If yes, what system?

( ) Hand files. If yes, what system?

( ) Apical Locator

( ) Others: Which ones?

2.8. Which technique do you use in the root canal prepare?

( ) Crown-down technique ( ) Down-Crown technique

2.9. How much time do you think is necessary to conclude endodontic treatment in one session?

Incisors:

( ) I do not perform

( ) up to $30 \mathrm{~min}$

( ) up to $60 \mathrm{~min}$

( ) up to $90 \mathrm{~min}$

( ) more than $90 \mathrm{~min}$
Premolars:

( ) I do not perform

( ) up to $30 \mathrm{~min}$

( ) up to $60 \mathrm{~min}$

( ) up to $90 \mathrm{~min}$

( ) more than $90 \mathrm{~min}$
Molars:

( ) I do not perform

( ) up to $30 \mathrm{~min}$

( ) up to $60 \mathrm{~min}$

( ) up to $90 \mathrm{~min}$

( ) more than $90 \mathrm{~min}$ 